\title{
Moisture content (MC) and multinuclear magnetic resonance imaging (MRI) study of water absorption effect on wood treated with aminofunctional silane
}

\author{
Bartłomiej Mazela · Joanna Kowalczuk • \\ Izabela Ratajczak · Kinga Szentner
}

Received: 8 October 2012/Published online: 15 December 2013

(C) The Author(s) 2013. This article is published with open access at Springerlink.com

\begin{abstract}
The aim of this study was to determine susceptibility of aminoethyl aminopropyl trimethoxysilane (AEAPTMOS)-treated wood to absorption of liquid water. Absorbability was analysed by measuring absolute moisture content of wood and by MRI. These analyses were based on the results of previous studies on resistance against decay fungi in case of wood treated with the same chemical compound. In their previous studies the authors found that AEAPTMOS exhibits enhanced hydrophobic properties and thus increased resistance to the action of specific abiotic and biotic factors. The advantageous fungicidal properties of wood treatment systems indicate that AEAPTMOS may be considered as an environmentally friendly solution, being an alternative to conventional biocidal agents. Results indicate that this method may be used in laboratory analyses assessing the relative amount of water uptake through the wood surface.
\end{abstract}

B. Mazela

Institute of Wood Chemical Technology, Poznan University of Life Sciences, Wojska Polskiego 28, 60637 Poznan, Poland

J. Kowalczuk

Department of Nuclear Magnetic Resonance, Institute of

Molecular Physics Polish Academy of Sciences, Poznan, Poland

I. Ratajczak $(\bowtie) \cdot$ K. Szentner

Department of Chemistry, Poznan University of Life Sciences,

Wojska Polskiego 75, 60625 Poznan, Poland

e-mail: ipolus@up.poznan.pl
Untersuchung der Wasseraufnahme von mit aminofunktionellem Silan behandeltem Holz über den Feuchtegehalt und mittels Magnetresonanztomographie

Zusammenfassung Ziel dieser Studie war es, den Einfluss einer Behandlung von Holz mit Aminoethylaminopropyltrimethoxysilan (AEAPTMOS) auf die Aufnahme von flüssigem Wasser zu bestimmen. Die Absorptionsfähigkeit wurde durch Untersuchung des absoluten Feuchtegehalts von Holz und mittels Magnetresonanztomographie (MRI) ermittelt. Als Grundlage dieser Studie dienten Ergebnisse früherer Untersuchungen über die Fäuleresistenz von mit der gleichen chemischen Verbindung behandeltem Holz. Die Autoren kamen darin zu dem Schluss, dass AEAPTMOS verbesserte hydrophobische Eigenschaften bewirkt und somit die Resistenz gegenüber bestimmten abiotischen und biotischen Faktoren erhöht. Die guten fungiziden Eigenschaften dieser Holzbehandlungsmethode deuten darauf hin, dass AEAPTMOS als umweltfreundliche Lösung angesehen werden kann und eine Alternative zu herkömmlichen Biozidmitteln darstellt. Die Ergebnisse zeigen, dass diese Methode in Laboruntersuchungen zur Bestimmung der relativen Menge an durch das Holz aufgenommenem Wasser verwendet werden kann.

\section{Introduction}

Magnetic resonance is currently a commonly applied imaging method, making it possible to obtain considerable image resolution. A necessary pre-condition for its applicability is the presence of a sufficient amount of water in the analysed material. The content of bound water in dry wood is too low, thus only wood with 
absolute moisture content (MC) exceeding $10 \%$ may be used in imaging.

Since the experiments conducted by Paul Lauterbur, magnetic resonance imaging (MRI) has been further developed. Many imaging techniques using this method and mainly based on Fourier transformation have been elaborated. Continuous technological progress has led to an improvement of sensitivity and resolution of this technique. As a result the magnetic resonance microimaging method has been developed. The term microimaging means that resolution attainable using this technique may be around a dozen micrometers in relation to objects containing water or other liquids. In order to obtain a magnetic resonance image, being a map of intensity of a nuclear signal in magnetic resonance, the MRI signal is dependent on the location of an element in the examined object. This dependence is referred to as spatial coding and is obtained using gradients of the magnetic field. Elements of such a map are called pixels (picture elements) in case of a 2-D image, or voxels (volume elements) in case of 3-D images. The greater the amplitude of the recorded signal, the lighter these elements are. Intensity of an image element is influenced by different parameters, directly connected with physical and chemical properties of the examined object. The most important ones include: spin density (i.e. the number of spins involved in resonance, found in a unit of volume); spin-lattice relaxation time $\mathrm{T}_{1}$ and spin-spin relaxation time $\mathrm{T}_{2}$; diffusion $-\mathrm{a}$ random movement of particles; and chemical shift, in comparison to other techniques a truly unique parameter, making it possible to observe spatial distribution of components with a specific chemical composition.

This high number of contrast parameters, unprecedented in comparison to other imaging methods, as well as the method's non-invasiveness constitute a major advantage of MRI. The above mentioned parameters may be used to obtain images or maps providing information on spatial properties of the analysed object. This technique makes it possible to select any observation plane for an object with no need to destroy it as a consequence of mechanical working. This means that the same object may repeatedly be tested. This gives researchers unlimited possibility to follow processes causing changes occurring over extended periods of time. Based on this potential of MRI (Dvinskikh et al. 2011; MacMillan et al. 2002; Rosenkilde and Glover 2002; Meder et al. 2003; Hameury and Sterley 2006) it was decided to apply this technique in studies on water uptake by wood pre-treated with an organosilicon solution.

Superficial treatments of organosilicon show potential improvement of water repellent characteristics in solid wood (Ratajczak et al. 2010, 2012; De Vetter et al. 2011). Most wood defects result from its hydrophilic character, thus organosilicon compounds comprise an important group not only due to their low toxicity, but also exceptional hydrophobic properties. Effectiveness of organosilicon compounds is varied, since it depends on many factors, e.g. the applied treatment method, type and amount of silane as well as the presence of other adjuvants.

As has been documented in many studies, chemical modification changes the surface wettability of wood to water. In most cases, this characteristic is not the primary aim of the modification, but it is desirable for wood in outdoor use. Sèbe and Brook (2001) reacted the surface of wood with organosilicon polymers in order to change the wettability characteristics. Noting that any $\mathrm{Si}-\mathrm{O}-\mathrm{C}$ linkages that may be formed with wood using a conventional reaction were subject to hydrolysis reactions, they utilized an alternative method for ensuring that the bond between the wood and the siloxanes was stable. The wood was first reacted with maleic anhydride and then allyl glycidyl ether, to give oligoesterifed wood. The modified wood was then reacted with either bis(trimethylsiloxy)methylsilane, hydride-terminated polydimethylsiloxane or platinumdivinyltetramethyldisiloxane. The contact angles of water on modified and unmodified wood were measured on the tangential, radial and transverse surfaces. Modification with the silicon reagents was found to render the wood extremely hydrophobic, even though there was no evidence for the reaction using IR spectroscopy, or any weight gain due to the reaction. However, XPS clearly showed the presence of silane on the wood surface, and removal of the top layer of the wood resulted in a significant decrease in the contact angle on the surface. It would seem that the reported high levels of water repellency required only very low levels of siloxane on the wood surface.

Chemical wood modification with silicon compounds results in a change of hygroscopic properties of wood, thus reducing negative effects of exposure to water and steam, and as a consequence it protects against fungal development (Sèbe and Brook 2001; Hill et al. 2004; Tingaut et al. 2005; Donath et al. 2006; Mazela et al. 2007; Panov and Terziev 2009). Different aminofunctional silanes were tested for their suitability to preserve wood against basidiomycetes. Donath et al. (2006) showed that the antifungal effect is caused by the amino groups, while alkyl groups, which influence the water uptake of wood, play a minor role. For effective protection, acidic conditions of the treatment solution are important; this promotes the formation of cationised amino groups (ammonium).

The aim of this study was to determine susceptibility of aminoethyl-aminopropyl trimethoxysilane (AEAPTMOS) treated wood to water uptake. Water uptake was analysed by measuring wood MC and by MRI. Earlier results regarding its biological resistance to wood destroying fungi were the reason for the present study (Mazela et al. 2013). 


\section{Materials and methods}

Wood of Scots pine (Pinus sylvestris L.) in the form of blocks was used for water uptake measurement and MRI analysis. All samples were cut from one strip so that annual rings were parallel to one edge. The average number of annual rings was 8 per $1 \mathrm{~cm}$.

Oven dried samples with the dimensions $30 \times 30 \times$ $10 \mathrm{~mm}^{3}$ (last dimension along the grain) were used for water uptake measurement. They were vacuum treated with AEAPTMOS solution in organic solvent (benzine) at different concentrations: $0.6 ; 3.0 ; 6.0$ and $12.0 \%$. The silane retention in wood was: $4.6 ; 20.5 ; 43.5$ and $87.0 \mathrm{~kg} / \mathrm{m}^{3}$ according to the solution concentration. After seasoning at a temperature of $20{ }^{\circ} \mathrm{C}$ and $60 \%$ relative humidity, samples reached $6.4 ; 7.7 ; 11.4 ; 13.2 \% \mathrm{MC}$, respectively. The untreated blocks (control samples) reached $6.19 \% \mathrm{MC}$ as a result of storage under the same conditions. The samples prepared in this way were soaked in water for nearly 50 days.

\subsection{MRI measurement}

MRI experiments were performed with a AVANCE $300 \mathrm{MHz}$ spectrometer (Bruker, Germany), equipped with a micro imaging probehead, magnetic field gradients, and Para Vision software. The static B0 field of $7.05 \mathrm{~T}$ corresponds to a $1 \mathrm{H}$ resonance frequency of $300.23 \mathrm{MHz}$. A Bruker imaging probehead Micro 2.5 was used with a $20 \mathrm{~mm}$ birdcage coil. This probehead facilitates application of pulse gradients up to $1 \mathrm{~T} / \mathrm{m}$.

The progress of solvent diffusion into the wood samples was studied by a single-slice multi-echo pulse sequence based on the Carr-Purcell-Meiboom-Gill (CPMG) echo sequence (Callaghan 1991; Blumich 2000; Meiboom and Gill 1958). The intensity of the image signal is given by the following Eq. (1):

$S=\rho(r)\left[1-\exp \left\{-\frac{T_{R}}{T_{1}(r)}\right\}\right] \exp \left\{\frac{\tau}{T_{2}(r)}\right\}$

where $\rho(r)$ is the spin density, T2 the spin-spin relaxation time, $\mathrm{T} 1$ the spin-lattice relaxation time, $\tau$ the echo time and TR the repetition time. As seen in Eq. (1), image intensity depends on T2, T1 and $\rho(r)$. However, when TR is sufficiently long (5 times $\mathrm{T} 1$ ) the $\mathrm{T} 1$ contrast can be eliminated from the images (Callaghan 1991; Blumich 2000; Kimich 1997). This condition was fulfilled in the current experiments.

The images were taken for a slice from the middle of the samples, along the horizontal direction (Fig. 1) with a repetition time TR of $7 \mathrm{~s}$. The acquisition parameters were a field of view (FOV) of $25 \times 25 \mathrm{~mm}^{2}$, digitized into $128 \times 128$ pixels with a slice thickness of $1 \mathrm{~mm}$ (i.e., each voxel $=195 \mu \mathrm{m} \times 195 \mu \mathrm{m} \times 1 \mathrm{~mm}$ ). $\quad$ MRI is very

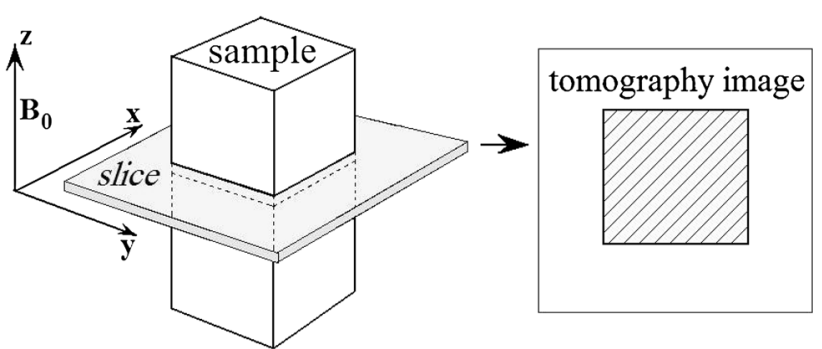

Fig. 1 Imaging of the sample

Abb. 1 Darstellung des Prüfkörpers

sensitive to mobile protons and the images were acquired with parameters which guaranteed that the signal intensities throughout the images were directly related to the solution concentration within the wood structure.

An oven dried sample with a density $\rho_{0}=0.4786 \mathrm{~g} / \mathrm{cm}^{3}$ and dimensions $10 \times 10 \times 20 \mathrm{~mm}^{3}$ (last dimension along the grain) was used for MRI analysis. It was soaked in water for $24 \mathrm{~h}$. Afterwards the sample was removed from the water, surface dried with blotting paper and weighed in order to determine the amount of water uptake. Due to the water uptake in an amount of $377 \mathrm{mg}$, wood MC increased to almost $40 \%$. Next, the sample was subjected to MRI analysis in order to create a tomographic image based on the profile of proton density at its edge (Fig. 3).

After generation of the first tomographic image, the sample was dried in an exsiccator over supersaturated potassium carbonate solution. In the course of drying, two additional MRI spectrometric analyses were performed at a wood $\mathrm{MC}=27.2 \%$ and $\mathrm{MC}=11.5 \%$ (i.e., after 96 and $192 \mathrm{~h}$ from the moment of first density proton imaging). After 10 days of drying, wood MC was $10.1 \%$ which prevented further signal recording.

After 12 days of drying under the above mentioned conditions, the same sample at a relative MC of $8.0 \%$ was soaked in a $3 \%$ AEAPTMOS solution in organic solvent. The sample was treated for $24 \mathrm{~h}$ obtaining silane retention at $3.7 \mathrm{~kg} / \mathrm{m}^{3}\left(\rho=0.6513 \mathrm{~g} / \mathrm{cm}^{3}\right)$. Next, in the same way as in the case of water treatment, the sample was subjected to MRI analysis providing another tomographic image (Fig. 4), where the protons come from the silane and the solvent.

The sample was dried again in the presence of supersaturated potassium carbonate solution. Drying progressed much faster than in the case of the same sample previously treated with water. After $48 \mathrm{~h}$ of drying, the sample was subjected to spectrometric analysis creating another proton density profile. The calculated wood MC was as high as $18.0 \%$. After $96 \mathrm{~h}$ the signal coming from protons was so weak that it prevented the generation of a tomographic image. After $144 \mathrm{~h}$ of drying, the same sample previously treated with AEAPTMOS solution was soaked again in water for $24 \mathrm{~h}$ (Fig. 5). 

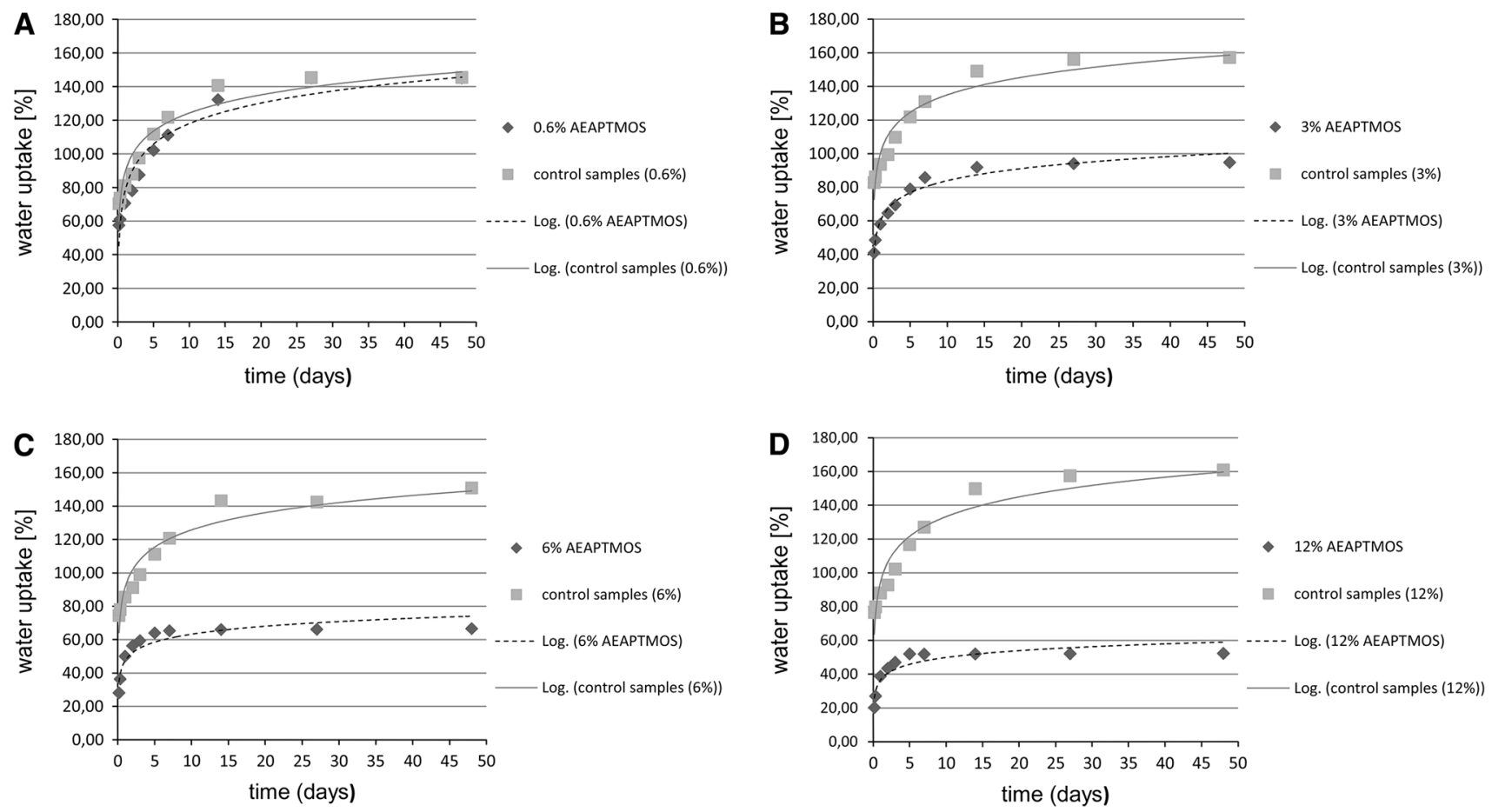

Fig. 2 Water soaking curves for wood samples treated with a $0.6 \%$; b $3 \%$; c $6 \%$ and d $12 \%$ of AEAPTMOS concentration solution Abb. 2 Wasseraufnahme in Abhängigkeit der Dauer der Wasserlagerung der Prüfkörper, die mit a $0,6 \%$, b $3 \%$, c $6 \%$ und d $12 \%$ AEAPTMOS-Konzentrationen behandelt wurden

\section{Results and discussion}

\subsection{Results of water uptake}

Wood primarily treated with $0.6 \%$ AEAPTMOS solution and then soaked in water, showed a water uptake which was only $8 \%$ lower than the values recorded for the control samples.

Samples treated with AEAPTMOS solution at a higher concentration than $0.6 \%$ showed a markedly smaller water uptake. Water uptake for samples treated with 3,6 and $12 \%$ AEAPTMOS solution amounted to 95, 67 and 52\%, respectively. Curves for the course of water uptake are given in Fig. 2.

\subsection{MRI results}

The proton profile shown in Fig. 3, due to the wood MC changes, illustrates the inverse process of water soaking during wood treatment. Peaks and valleys reflect the diverse structure of the wood with the prevalence of earlyand latewood. Figure 3 shows the profiles of protons come from water. The intensity of theses profiles corresponds with the amount of water inside the wood structure and shows the gradual decrease of intensity due to the drying time. The profile shows that the intensity of protons

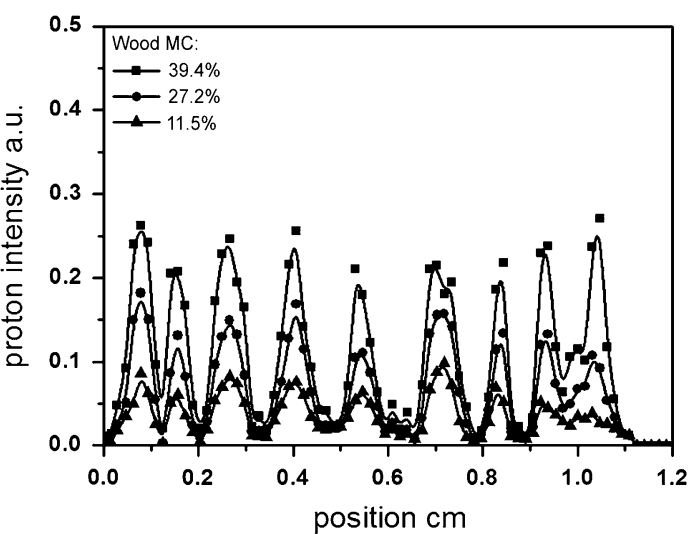

Fig. 3 Water proton density profile in unmodified wood sample due to the drying time

Abb. 3 Dichteprofil der Wasserprotonen in unbehandelten Prüfkörpern bei unterschiedlicher Trocknungszeit

identified in earlywood is not varied due to the changes of wood MC. This confirms the low water capacity of earlywood. The wide variation in the intensity of protons can be observed in the areas of latewood, which proves high treatability of this part of wood.

Figure 4 shows the profile of protons comes from silane and solvent taken during the drying time of the wood sample previously treated with silane. 


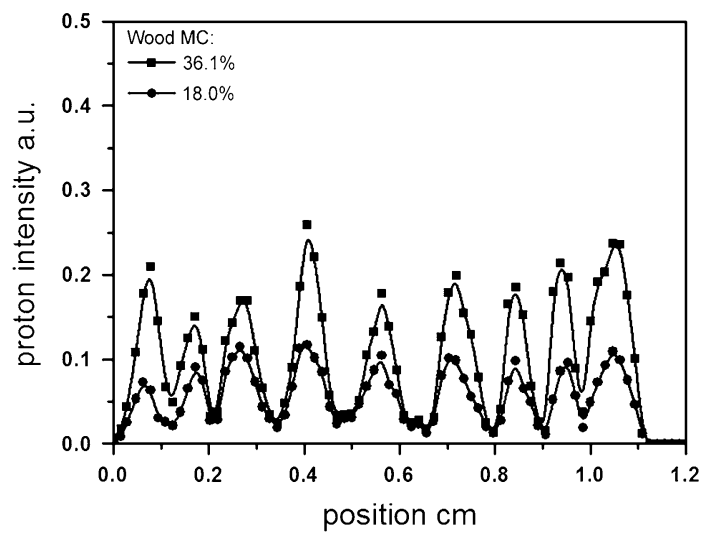

Fig. 4 Proton density profile in AEAPTMOS modified wood due to the drying time

Abb. 4 Dichteprofil der Wasserprotonen in mit AEAPTMOS behandelten Prüfkörpern bei unterschiedlicher Trocknungszeit

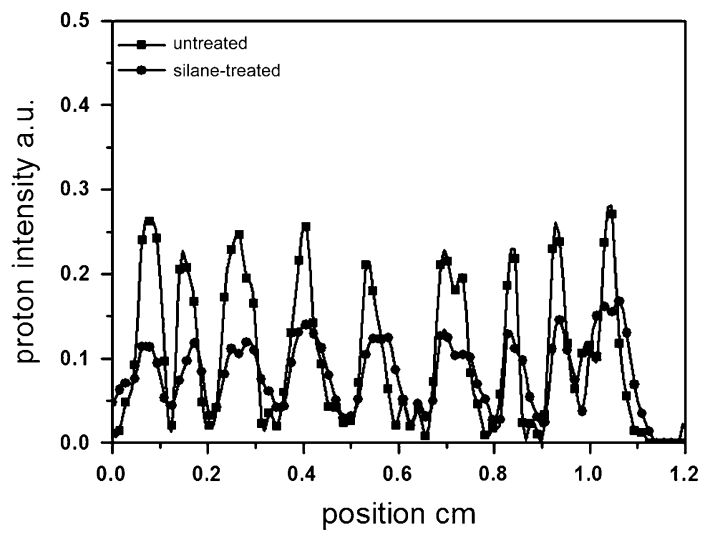

Fig. 5 Profiles of water protons in untreated and silane-treated wood sample after water soaking

Abb. 5 Wasserprotonprofil in unbehandelten und mit Silan behandelten Prüfkörpern nach Wasserlagerung

Figure 5 shows the change of proton profiles of the sample soaked in water and the same sample treated with AEAPTMOS and soaked in water again. Both samples were treated with water for $24 \mathrm{~h}$. It should be noted that, after almost $100 \mathrm{~h}$ of drying, the intensity of protons of the test sample (treated with silane, and then soaked in water) is much lower than for the control (untreated, water-soaked).

\section{Conclusion}

Analysis performed using magnetic resonance (MRI) confirmed the hydrophobation capacity of AEAPTMOS solution applied on pine wood surface at a relatively low concentration, shown in the analyses of water uptake. Moreover, this method made it possible to monitor the penetration capacity of both liquids, i.e. both the tested silane solution and water, for the same wood sample in a precisely determined anatomical direction.

On the basis of the conducted analyses it may be assumed that the magnetic resonance technique may be further applied to determine changes in the liquid content in wood, in this way evaluating its absorbability. The experiment conducted by the authors" team concerned a potential to reduce water absorption by wood thanks to its previous impregnation with a selected organosilicone compound. An advantage of this solution stems from the fact that an organosilicone solution, in contrast to other hydrophobic agents, does not form a coating on the wood surface. In this way wood retains its natural appearance.

The results indicate that this method may be used in laboratory analyses assessing wood penetration depth of a liquid and constitute the basis for the development of a research method measuring the degree of hydrophobicity of wood surfaces.

Acknowledgments The work was financially supported by the Ministry of Science and Higher Education as the N N309 28763 research grant as well as by the National Centre for Research and Development of Poland supported by Norway Grants as a part of Polish-Norwegian Research Programme as the DURAWOOD project Pol-Nor/203119/32.

Open Access This article is distributed under the terms of the Creative Commons Attribution License which permits any use, distribution, and reproduction in any medium, provided the original author(s) and the source are credited.

\section{References}

Blumich B (2000) NMR imaging of materials. Oxford Sci Publ, New York

Callaghan PT (1991) Principles of nuclear magnetic resonance microscopy. Oxford Sci Publ, New York

De Vetter L, Van den Bulcke J, Van Acker J (2011) Envelope treatment of wood based materials with concentrated organosilicons. Eur J Wood Prod 69(3):97-406

Donath ST, Militz H, Mai C (2006) Treatment of wood with aminofunctional silanes for protection against wood destroying fungi. Holzforschung 60(2):210-216

Dvinskikh SV, Henriksson M, Mendicino AL, Fortino S, Toratti T (2011) NMR imaging study and multi-Fickian numerical simulation of moisture transfer in Norway spruce samples. Eng Struct 33:3079-3086

Hameury S, Sterley M (2006) Magnetic resonance imaging of moisture distribution in Pinus sylvestris L. exposed to daily indoor relative humidity fluctuations. Wood Mater Sci Eng 1(3-4):116-126

Hill CAS, Farahani MMR, Hale MDC (2004) The use of organoalkoxysilane coupling agents for wood preservation. Holzforschung 58(3):316-325

Kimich R (1997) NMR tomography, diffusometry, relaxometry. Springer, Heidelberg

MacMillan MB, Schneider MH, Sharp AR, Balcom BJ (2002) Magnetic resonance imaging of water concentration in low moisture content wood. Wood Fibre Sci 34(2):276-286 
Mazela B, Kloc M, Bartkowiak M (2007) Physical properties of wood treated with silanes and siloxanes. Ann WULS SGGW For Wood Technol 62:26-30

Mazela B, Hochmanska P, Krystofiak T (2013) Performance of biocide-free preservative-protective systems modified with organosilicon compounds. The International Research Group on Wood Protection, Doc. IRG/WP 13-30628

Meder R, Codd SL, Franich RA, Callaghan PT, Pope JM (2003) Observation of anisotropic water movement in Pinus radiata D. Don wood using magnetic resonance micro-imaging. Holz RohWerkst 61(4):251-256

Meiboom S, Gill D (1958) Moisture content during drying of wood using a novel magnetic resonance imaging. Rev Sci Instrum 29:688-691

Panov D, Terziev N (2009) Study on some alkoxysilanes used for hydrophobation and protection of wood against decay. Int Biodeterior Biodegrad 63(4):456-461

Ratajczak I, Wichłacz-Szentner K, Mazela B, Hochmańska P, Rissmann I (2010) Silicon compounds as additives improving coating performance: fixation of silicon compounds with cellulose. Eur J Wood Prod 68:483-486

Ratajczak I, Szentner K, Rissmann I, Mazela B, Hochmańska P (2012) Treatment formulation based on organosilanes and plant oil blend - reactivity to wood and cellulose. Wood Res 57(2):265-270

Rosenkilde A, Glover P (2002) High resolution measurement of the surface layer moisture content during drying of wood using a novel magnetic resonance imaging technique. Holzforschung 56:312-317

Sèbe G, Brook MA (2001) Hydrophobation of wood surfaces: covalent grafting of silicone polymers. Wood Sci Technol 35(3):269-282

Tingaut P, Wiegenand O, Mai C, Millitz H, De Jéso B, Sebe G (2005) Functionalisation of wood by reaction with 3-isocyanatopropyltriethoxysilane: grafting and hydrolysis of the triethoxysilane end groups. Holzforschung 59:397-404 